\title{
Northern Alberta Health Libraries Association
}

Fall and winter were full of successes for the Northern Alberta Health Libraries Association (NAHLA) and its members.

In the fall, Liza Chan, Research Librarian, Alberta Innovates Health Solutions, taught a workshop on searching for grey literature. In January, a virtual forum was held on the Canadian Virtual Health Library (CVHL), which was followed by a second searching workshop in the spring, taught by Linda Slater, on searching PubMed. NAHLA's annual Teaching, Research, Education, "Nowledge", Direction, Strength mini-conference was held in April. Keynote addresses by Neil Seeman, Director, Health Strategy Innovation Cell, Massey College, University of Toronto and Dorothy McLachlan, Alberta Health Services, set the tone for an afternoon of learning. Soleil Surette, Department of Pediatrics, University of Alberta, presented her content analysis of Canadian Health Libraries Association / Association des bibliothèques de la santé du Canada (CHLA / ABSC) abstracts. Dr. Lisa Given, School of Library and Information Studies, had preliminary results from her Canadian Institutes of Health Research (CIHR) funded project on exploring decision making and information behaviour around H1N1 by pregnant women and seniors. The final presentation was by Dr. Lisa Cranley, Faculty of Nursing, University of Alberta, on facilitating knowledge transfer among health professionals.

Congratulations go out to Trish Chatterley, Soleil Surette, Liz Dennett, and Devon Greyson who received a Chapter Initiative Grant from CHLA / ABSC for their research project on embedded librarianship. NAHLA is very proud to have been able to support its members in their application. NAHLA and the Southern Alberta Heritage Language Association (SAHLA) worked together to fund two Alberta library students to attend the CHLA / ABSC annual conference in Calgary. NAHLA is happy to be able to support Janine Eckert in her first visit to the conference. More congratulations go out to other NAHLA members: Shelagh Genuis is the recipient of NAHLA's Continuing Education Award, Shelagh will be presenting findings from her doctoral dissertation at CHLA / ABSC; Trish Chatterley is the recipient of the EBSCO / MLA Annual Meeting Grant, this grant provides $\$ 1000$ to attend the Medical Library Association's annual meeting in Minneapolis, Minnesota, this year; Thane Chambers is the recipient of MLA's Donald A.B. Lindberg Research Fellowship, this Fellowship provides up to $\$ 10000$ for a research project, she will use the funds for a research project on the roles and perceptions of academic health librarians in health research.

\author{
Thane Chambers \\ President, NAHLA \\ Faculty of Nursing Research Librarian \\ Public Services Librarian \\ J.W. Scott Health Sciences Library \\ Research Office \\ Faculty of Nursing 4-103 Clinical Sciences Building \\ Edmonton, AB T6G 2G3, Canada
}

